Estudos RBEP

\title{
Implantação e implementação do Proinfo no município de Bataguassu, Mato Grosso do Sul: o olhar dos profissionais da educação
}

Carla Busato Zandavalli

Dirceu Martins Pedrosa

\section{Resumo}

Expõe resultados de uma pesquisa desenvolvida em 2012 e 2013, com intuito de analisar o processo de implantação e implementação do Programa Nacional de Tecnologia Educacional (Proinfo), em Bataguassu/ Mato Grosso do Sul. O estudo de caso foi realizado em três fases: (a) revisão bibliográfica, análise de documentos do Estado de Mato Grosso do Sul e da legislação em vigor; (b) aplicação de questionários aos professores regentes e entrevista semiestruturada aos professores das Salas de Tecnologia Educacional (STEs) das referidas escolas; (c) sistematização e análise dos elementos coletados. Confrontados os dados obtidos, constatou-se que existe o reconhecimento dos professores pesquisados sobre a importância das STEs para o ensino, entretanto ele não se traduz na utilização adequada das tecnologias da informação e da comunicação (TICs), em função da resistência às TICs, da descontinuidade dos cursos ofertados pelo Proinfo, fragmentando a formação continuada desses docentes, bem como da carga horária trabalhada, considerada excessiva pelos sujeitos da pesquisa. Os resultados obtidos revelam a necessidade de mudanças nas políticas educacionais específicas quanto à melhoria das condições de trabalho dos professores e às condições efetivas de formação em serviço, para que seja concretizada a utilização crítica e criativa das TICs como instrumentos de mediação de conhecimentos. 
Palavras-chave: políticas educacionais; Programa Nacional de Tecnologia Educacional; tecnologia educacional; rede estadual de ensino; Bataguassu; Mato Grosso do Sul.

\section{Abstract \\ Establishment and implementation of Proinfo in the municipality of Bataguassu, in Mato Grosso do Sul: the view of education professionals}

This paper presents results of a survey conducted in 2012 and 2013 and analyzes the deployment and implementation of the National Educational Technology Program (Programa Nacional de Tecnologia Educacional - Proinfo) in urban state schools in Bataguassu, in the state of Mato Grosso do Sul. The case study was conducted in three phases: (a) literature review, analysis of documents related to the state of Mato Grosso do Sul, and the legislation in force; (b) application of questionnaires and semi-structured interviews to school teachers and to teachers of the Educational Technology Rooms (Salas de Tecnologia Educacional - STEs) of the investigated schools; (c) systematization and analysis of the collected data. Based on the data obtained, it was found that the research participant teachers recognize the importance of STEs for teaching. However, that fact does not necessarily correspond to the appropriate use of information and communications technology (ICT), due to the resistance to ICT, the discontinuity of courses offered by Proinfo, which interrupts the continuous training of these teachers, as well as teachers' workload, considered excessive by the research subjects. The results show the need for changes in specific educational policies: the improvement of working conditions of teachers; effective conditions of in-service training, in order to realize the critical and creative use of ICT as an instrument of mediation of knowledge.

Keywords: educational policies; National Educational Technology Program; educational technology; state education network; Bataguassu; Mato Grosso do Sul.

\section{Introdução}

Nas últimas décadas, a reordenação do setor produtivo tem provocado mudanças sociais, econômicas e culturais significativas, tendo como instrumentos importantes as Tecnologias da Informação e da Comunicação (TICs), que não são fins em si mesmas, mas ferramentas presentes nesse processo. Elas geram a necessidade do domínio de novos saberes para 
a interação no meio social e o exercício do trabalho. Essas mudanças adentram as escolas e as salas de aula, trazendo novas demandas, pois a comunidade escolar reclama pela atualização e capacitação de professores.

As TICs, quando utilizadas com base em pressupostos teóricos claros e coerentes, mostram-se relevantes no campo educacional e podem proporcionar ao docente novas ferramentas para sua prática pedagógica, o que requer, necessariamente, a formação dos professores, haja vista que são eles os principais atores, no âmbito escolar, na mediação do conhecimento e no estímulo ao desenvolvimento intelectual e social do aluno. Se o computador pode ser uma das ferramentas para auxiliar esse desenvolvimento, o professor necessita saber utilizá-lo com competência e clareza de princípios e objetivos.

A capacitação em serviço está prevista como um dos fundamentos na formação de professores, como aponta o parágrafo único do art. 61 da Lei de Diretrizes e Bases da Educação Nacional (Lei nº 9.394, de 20 de dezembro de 1996):

\begin{abstract}
Parágrafo único. A formação dos profissionais da educação, de modo a atender às especificidades do exercício de suas atividades, bem como aos objetivos das diferentes etapas e modalidades da educação básica, terá como fundamentos (Incluído pela Lei n 12.014, de 2009):

[...]

II - a associação entre teorias e práticas, mediante estágios supervisionados e capacitação em serviço (Incluído pela Lei nº 12.014, de 2009).
\end{abstract}

Desde a aprovação das Diretrizes Curriculares Nacionais para a Formação de Professores da Educação Básica, instituída por meio da Resolução CNE/CP n 1, de 18 de fevereiro de 2002, os currículos vêm sofrendo modificações e contemplando a utilização das TICs:

Art. $2^{\circ}$ A organização curricular de cada instituição observará, além do disposto nos artigos 12 e 13 da Lei 9.394, de 20 de dezembro de 1996, outras formas de orientação inerentes à formação para a atividade docente, entre as quais o preparo para:

$[\ldots]$

VI - o uso de tecnologias da informação e da comunicação e de metodologias, estratégias e materiais de apoio inovadores [...]. (Brasil. CNE, 2002).

A partir dos anos 2000, uma parcela de professores tem recebido mais informações sobre as TICs na sua formação inicial, melhorando sua qualificação para o uso crítico e pedagógico das tecnologias. No entanto, tais conhecimentos, muitas vezes, não estão sendo colocados em prática na mesma proporção em que chegam à sociedade contemporânea, pois há uma série de condicionantes que dificulta essa prática, como a própria infraestrutura tecnológica das escolas.

Pesquisas realizadas por Cysneiros (1999), Valente (1998; 2005) e Valente e Almeida (1997) imputam grande parte dos problemas 
constituídos na área educacional ao despreparo dos profissionais, à falta de aporte teórico-metodológico e prático e à inconsistência das propostas de ensino.

Além dos problemas relativos à formação inicial e continuada de professores, não é possível ignorar as condições de trabalho inadequadas, materializadas em salas superlotadas, baixos salários, longa jornada de trabalho - que chega a superar 60 horas semanais - e trabalho extra ao da sala de aula. Todos esses aspectos se fundem para trazer dificuldades ao processo de ensino e de aprendizagem, e a eles se somam as dificuldades em acessar e utilizar as TICs.

Saviani (2003, p. 75), ao tratar sobre o papel da escola, afirma que ela deve "[...] possibilitar o acesso das novas gerações ao mundo do saber sistematizado, do saber metódico, científico. Ela necessita organizar processos, descobrir formas adequadas a essa finalidade".

As TICs são ferramentas importantes para favorecer tal mediação, mas são inúteis nas mãos de profissionais que não dominam as bases teórico-metodológicas da educação. Cysneiros (1999, p. 18) corrobora com tal ideia:

A presença da tecnologia na escola, mesmo com bons softwares, não estimula os professores a repensarem seus modos de ensinar nem os alunos a adotarem novos modos de aprender. Como ocorre em outras áreas da atividade humana, professores e alunos precisam aprender a tirar vantagens de tais artefatos. Um bisturi a laser não transforma um médico em bom cirurgião, embora um bom cirurgião possa fazer muito mais se dispuser da melhor tecnologia médica, em contextos apropriados.

As políticas públicas voltadas à formação continuada de docentes devem abranger as TICs, mas não podem descurar das lacunas existentes na formação inicial dos professores no que toca aos fundamentos da educação, aos próprios conteúdos a serem ensinados e suas metodologias. A situação ideal implicaria trabalhar a articulação desses elementos nos processos de formação continuada.

Valente e Almeida (1997, p. 11) consideram que há uma forte contradição entre a entrada dos computadores nas escolas, objetos modernos, acompanhados de velhas práticas transmissoras:

A análise das experiências realizadas nos permite entender que a promoção dessas mudanças pedagógicas não depende simplesmente da instalação de computadores nas escolas. É necessário repensar a questão da dimensão do espaço e do tempo da escola. A sala de aula deve deixar de ser o lugar de carteiras enfileiradas para se tornar um local em que professor e alunos podem realizar um trabalho diversificado em relação ao conhecimento. O papel do professor deixa de ser o de "entregador" de informação, para ser o de facilitador do processo de aprendizagem. O aluno deixa de ser passivo, de ser o receptáculo das informações, para ser ativo aprendiz, construtor do seu conhecimento.

No âmbito do uso das TICs na escola, observam-se ainda a resistência de professores às tecnologias, a necessidade de aquisição de equipamentos, 
capacitação dos professores, produção de softwares educacionais de qualidade, disponibilização de recursos, entre outros. Tais problemas já eram relatados por Cisneyros (1998, p. 12, apud Velanga, 2010, p. 146) no final dos anos 1990, momento da implantação do Programa Nacional de Tecnologia Educacional (Proinfo) em muitos Estados brasileiros:

[...] embora haja o interesse na formulação de políticas públicas de introdução de novas tecnologias nos sistemas educacionais, [...]. Novos estudos apontam como prováveis causas do insucesso: falta de recursos, resistência dos professores, burocracia institucional, despreparo dos professores e equipamentos inadequados.

A partir da observação dessa problemática mais ampla e das condições concretas de realização das práticas pedagógicas nas escolas públicas em Bataguassu, delineou-se como principal objetivo deste estudo identificar e analisar a percepção dos professores da rede estadual de ensino de Mato Grosso do Sul sobre a implantação e implementação do Proinfo na zona urbana do município de Bataguassu.

A relevância desta investigação se dá mediante a importante entrada das TICs na sociedade contemporânea, no mundo do trabalho e nas práticas sociais, inclusive em municípios pequenos e com predomínio de áreas rurais em seu entorno, como é o caso de Bataguassu. As características econômicas do município acentuam ainda mais a importância deste estudo, em razão da ênfase na base essencialmente primária, o que gera maior resistência e dificuldade de acesso às TICs. Destacam-se, também, a presença cada vez mais acentuada das redes sociais no cotidiano dos estudantes, dos professores e da sociedade em geral e a inexistência, nas bases de dados selecionadas para este estudo, de pesquisas sobre o desenvolvimento do Proinfo em Bataguassu.

Dado o corte específico, foi realizado um estudo de caso - tendo como público-alvo professores do $1^{\circ}$ ao $5^{\circ}$ ano do ensino fundamental e os profissionais (gestores ou monitores) das Salas de Tecnologias Educacionais (STEs) da rede pública estadual urbana de Bataguassu visando atender algumas finalidades específicas: a) analisar se as ações realizadas na rede estadual urbana do município cumprem os objetivos do Proinfo e identificar a percepção dos professores acerca da qualidade e da adequação dos processos de capacitação direcionados para o uso do computador na escola; b) verificar os fatores que facilitam e os que dificultam o desenvolvimento do professor para integrar esse recurso à sua prática pedagógica; c) identificar o nível de conhecimento dos profissionais da educação que atuam na referida rede estadual de ensino, considerando os aspectos da tecnologia educacional.

O município de Bataguassu possui quatro escolas da rede estadual na zona urbana, as quais contam com STEs e aderiram ao Proinfo.

Este artigo está estruturado em cinco partes: na primeira, abordam-se a origem e a implantação do Proinfo no Brasil e em Mato Grosso do Sul; na segunda, consta a metodologia da pesquisa; na terceira, descreve-se 
a percepção dos profissionais de educação de Bataguassu acerca do uso das TICs nas STEs. Nas partes finais, seguem a análise dos resultados e as conclusões.

\section{A implantação do Proinfo no Brasil e em Mato Grosso do Sul}

O Proinfo, criado pela Portaria $\mathrm{n}^{0}$ 522, de 9 de abril de 1997, desenvolvido pela Secretaria de Educação a Distância (Seed) ${ }^{1}$ em parceria com os governos estaduais e municipais, surge como uma expansão do Programa Nacional de Informática na Educação (Proninfe), tendo como principal atribuição a de introduzir o uso das TICs nas escolas públicas:

Art. $1^{\circ}$ Fica criado o Programa Nacional de Informática na Educação Proinfo, com a finalidade de disseminar o uso pedagógico das tecnologias de informática e telecomunicações nas escolas públicas de ensino fundamental e médio pertencentes às redes estadual e municipal. (Brasil. MEC, 1997, p. 1).

A partir de 12 de dezembro de 2007, mediante a publicação do Decreto $n^{\circ}$ 6.300, o Proinfo passou a denominar-se Programa Nacional de Tecnologia Educacional, tendo como principal objetivo promover o uso pedagógico das tecnologias de informação e comunicação nas redes públicas de educação básica, conforme preceitua o artigo $1^{\circ}$, nos itens I a III:

Art. $1^{\circ}$ O Programa Nacional de Tecnologia Educacional - Proinfo, executado no âmbito do Ministério da Educação, promoverá o uso pedagógico das tecnologias de informação e comunicação nas redes públicas de educação básica.

Parágrafo único. São objetivos do Proinfo:

I - promover o uso pedagógico das tecnologias de informação e comunicação nas escolas de educação básica das redes públicas de ensino urbanas e rurais;

II - fomentar a melhoria do processo de ensino e aprendizagem com o uso das tecnologias de informação e comunicação;

III - promover a capacitação dos agentes educacionais envolvidos nas ações do Programa. (Brasil. MEC, 2007).

O Proinfo tem na preparação de recursos humanos - os professores sua principal condição de sucesso. Eles são capacitados em dois níveis: os multiplicadores (responsáveis pelas capacitações) e os de escolas (aqueles que trabalham junto aos alunos). Adota-se no programa, portanto, o princípio de o professor capacitar o professor.

\subsection{O Proinfo em Mato Grosso do Sul e em Bataguassu}

Em Mato Grosso do Sul, a implantação do Proinfo começou a partir de 1997, por meio do Projeto Estadual de Informática na Educação.
${ }^{1}$ A Seed foi desativada em janeiro de 2011. 
A adesão da Secretaria de Estado de Educação de Mato Grosso do Sul (SED/MS) ao programa ocorreu com o intuito de

[...] instrumentalizar as escolas da rede estadual de Mato Grosso do Sul com recursos tecnológicos e humanos, no sentido de proporcionar a incorporação adequada das tecnologias computacionais e de rede, como suporte do processo pedagógico e administrativo. (Mato Grosso do Sul, 1997, p. 8).

Para oferecer maior suporte à implementação do Proinfo e à capacitação do pessoal da área de educação, foram criados os Núcleos de Tecnologia Educacional (NTEs), por meio do Decreto n ${ }^{\circ}$ 9.271, de 17 de dezembro de 1998. Os NTEs foram instalados abrangendo quatro regionais: Campo Grande (capital), Corumbá, Dourados e Três Lagoas. Cada qual atuando nos municípios sob sua jurisdição.

O Decreto $n^{\circ}$ 9.271/1998 foi revogado pelo Decreto $n^{\circ} 12.437$, de 31 de outubro de 2007, que definiu a nova organização dos NTEs, determinando:

I - acompanhar, orientar e avaliar o processo de implantação e implementação das salas de tecnologias educacionais;

II - responsabilizar-se pela formação continuada dos profissionais da educação em tecnologias educacionais;

III - oferecer subsídios técnicos e pedagógicos aos professores que atuam nas salas de tecnologias educacionais de forma que as atividades propostas contribuam para o sucesso do processo de ensino e aprendizagem;

IV - prestar assessoria técnico-pedagógica às escolas e Municípios no que diz respeito às tecnologias educacionais. (Mato Grosso do Sul, 2007).

Com a revogação do decreto anterior, os NTEs passaram a ser vinculados à Coordenadoria de Tecnologias Educacionais da Superintendência de Planejamento e Apoio à Educação, com sede nos municípios de Aquidauana, Campo Grande, Corumbá, Coxim, Dourados, Naviraí, Nova Andradina, Ponta Porã e Três Lagoas. No Decreto n 12.437, de 31 de outubro de 2007, aponta-se a criação de um NTE em Campo Grande, para atendimento aos municípios do entorno da capital.

Contudo, no segundo mandato do atual governo, foram realizadas algumas mudanças no que diz respeito aos NTEs. Revogou-se o Decreto $n^{\circ} 12.437 / 2007$, entrando em vigor o Decreto $n^{\circ} 13.421$, de 18 de maio de 2012, que trouxe como alteração a criação de mais dois NTEs, nos municípios de Jardim e Glória de Dourados.

No Quadro 1, estão identificados os municípios jurisdicionados em cada NTE. O novo decreto não alterou a jurisdição do município de Bataguassu, que permanece sob o NTE da cidade de Três Lagoas, conforme determinado em seu anexo. 


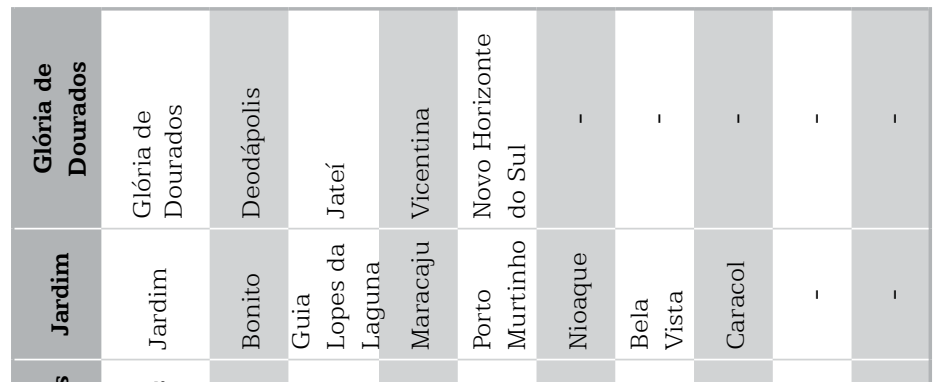

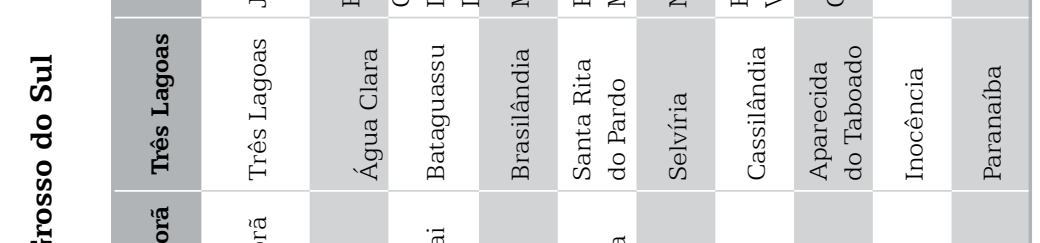

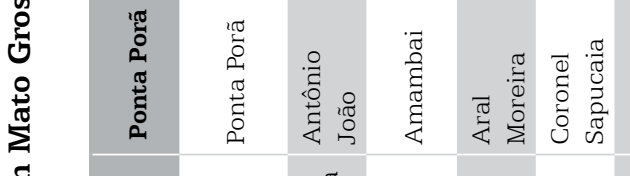

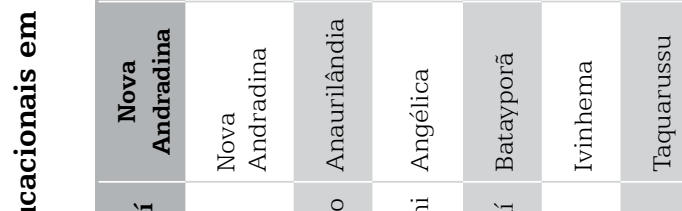

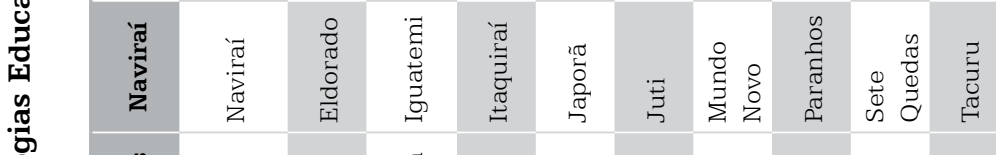

\begin{tabular}{|c|c|c|c|c|c|c|c|c|c|c|}
\hline $\begin{array}{l}\stackrel{0}{0} \\
\frac{0}{\pi} \\
\vdots \\
0\end{array}$ & $\begin{array}{l}0 \\
0 \\
0 \\
\Xi \\
\Xi \\
0\end{array}$ & 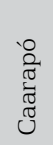 & 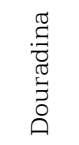 & 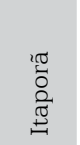 & 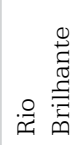 & 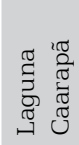 & 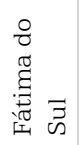 & I & ' & 1 \\
\hline ठี & $\begin{array}{l}\tilde{a} \\
0 \\
0\end{array}$ & 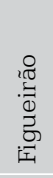 & 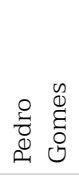 & 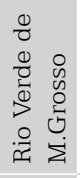 & 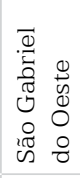 & $\begin{array}{l}\widetilde{0} \\
\tilde{0} \\
0 \\
0\end{array}$ & $\begin{array}{l}0 \\
0 \\
0 \\
0 \\
0 \\
0 \\
0 \\
4\end{array}$ & 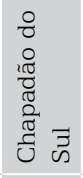 & 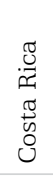 & \\
\hline نّ & 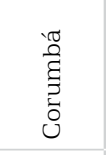 & 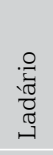 & I & I & 1 & ' & 1 & ' & , & ' \\
\hline 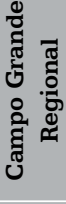 & 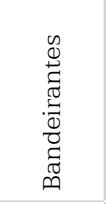 & 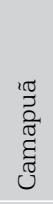 & 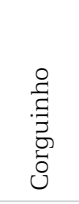 & 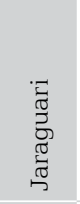 & 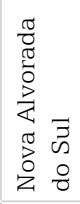 & 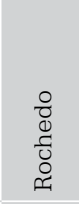 & 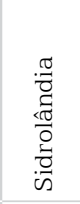 & 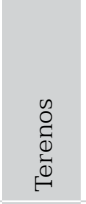 & 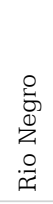 & 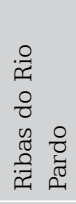 \\
\hline 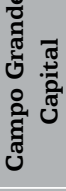 & 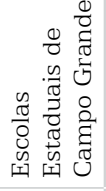 & 1 & ' & 1 & 1 & 1 & 1 & 1 & ' & ' \\
\hline 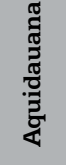 & 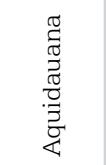 & 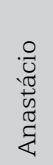 & 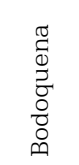 & 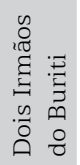 & $\begin{array}{l}\frac{\pi}{0} \\
\frac{0}{0} \\
\stackrel{0}{3}\end{array}$ & ' & ' & 1 & 1 & ' \\
\hline
\end{tabular}


As STEs e as atribuições dos professores das salas de informática foram instituídas por meio das seguintes resoluções emitidas pela SED/MS:

a) Resolução SED/MS n 1.570, de 4 de setembro de 2002. Dispõe sobre a lotação e atribuições de professor da educação básica para exercer a função de professor em sala de informática nas unidades escolares da rede estadual de ensino, e dá outras providências.

b) Resolução SED/MS n ${ }^{\circ} 1.842$, de 8 de abril de 2005. Revoga a Resolução SED/MS n 1.570/2002. Dispõe sobre a criação das Salas de Tecnologias Educacionais, a lotação e atribuições de professor da educação básica para exercer a função de professor regente nessas salas nas unidades escolares da rede estadual de ensino, e dá outras providências.

c) Resolução SED/MS n².127, de 5 de junho de 2007. Revoga a Resolução SED/MS n 1.842/2005. Dispõe sobre a implantação, implementação, monitoramento e avaliação das Salas de Tecnologias Educacionais na rede estadual de ensino, e dá outras providências.

d) Resolução SED/MS n 2.491, de 8 de dezembro de 2011. Revoga a Resolução SED/MS n 2.127, de 5 de junho de 2007. Dispõe sobre o Projeto de implementação das Salas de Tecnologias Educacionais (STEs) e a utilização das diversas tecnologias midiáticas nas unidades escolares da rede estadual de ensino, e dá outras providências.

Segundo os arts. $3^{\circ}$ e $4^{\circ}$ da Resolução n $2.491 / 2011$, as STEs estão vinculadas aos NTEs e às escolas em que estão instaladas da seguinte forma:

Art. $3^{\circ}$ As STEs constituem-se em dependências escolares, administrativas, pedagógicas e financeiramente vinculadas às escolas onde se encontram instaladas.

Art. $4^{\circ}$ As STEs são tecnicamente vinculadas aos Núcleos de Tecnologias Educacionais - NTEs/Coordenadoria de Tecnologia Educacional/ Superintendência de Políticas de Educação/Secretaria de Estado de Educação. (Mato Grosso do Sul, 2011).

O capítulo II, da mesma resolução, dispõe sobre a seleção e a lotação dos professores das STEs e trata do processo seletivo para compor o banco de candidatos, observando as seguintes etapas: (a) avaliação; (b) análise de currículo; e (c) entrevistas. Somente poderão participar professores com formação superior, habilitação e licenciatura plena. A seleção se dará mediante comprovação técnica e pedagógica, conforme vaga disponível na unidade escolar.

A implantação do Proinfo como iniciativa do governo estadual traduz-se numa perspectiva empreendedora no caminho para a modernidade e a inclusão digital, entretanto, é preciso que essa expectativa avance para além da instalação de equipamentos nos laboratórios de informática. 


\subsubsection{Proinfo em Bataguassu}

A cidade de Bataguassu possui quatro escolas que compõem a rede estadual urbana do município: as escolas estaduais Professor Braz Sinigáglia e Professor Luiz Alberto Abraham, que atendem do $1^{\circ}$ ao $9^{\circ}$ ano do ensino fundamental; e as escolas estaduais Manoel da Costa Lima e Peri Martins, que ofertam o ensino fundamental do $1^{\circ}$ ao $9^{\circ}$ ano e o ensino médio.

O Quadro 2 mostra a distribuição de computadores nas escolas da zona urbana de Bataguassu. A primeira escola contemplada foi a Professor Braz Sinigáglia, no ano de 2000, a distribuição continuou esporadicamente após o ano de 2006.

\section{Quadro 2 - Relatório de Distribuição por Programa e Contrato do Proinfo no Município de Bataguassu - Mato Grosso do Sul}

\begin{tabular}{|c|l|r|c|}
\hline \multicolumn{1}{|c|}{ Inep } & \multicolumn{1}{|c|}{ Razão social } & Contrato & Data da entrega \\
\hline 50013050 & EE Professor Braz Sinigáglia & $02 / 2000$ & N. Consta \\
\hline 50013025 & EE Manoel Costa Lima & $105 / 2006$ & $23 / 03 / 2007$ \\
\hline 50013033 & EE Peri Martins & $105 / 2006$ & $23 / 03 / 2007$ \\
\hline 50013025 & EE Manoel Costa Lima & $105 / 2006$ & $20 / 08 / 2012$ \\
\hline 50013033 & EE Peri Martins & $142 / 2008$ & $10 / 06 / 2010$ \\
\hline 50013050 & EE Professor Braz Sinigáglia & $89 / 2007$ & $13 / 07 / 2009$ \\
\hline 50024019 & EE Professor Luiz Alberto Abraham & $89 / 2007$ & $01 / 08 / 2008$ \\
\hline
\end{tabular}

Fonte: MEC/Sigetec.

Nota: $\mathrm{EE}=$ Escola Estadual.

Todas as escolas de rede estadual urbana de Bataguassu estão aparelhadas com STEs e integradas no programa Banda Larga na Escola (BLE), como exposto no Quadro 3.

\section{Quadro 3 - Relatório de Distribuição do Programa Banda Larga na Escola (BLE) no Município de Bataguassu - Mato Grosso do Sul}

\begin{tabular}{|c|l|c|c|}
\hline Inep & \multicolumn{1}{|c|}{ Razão Social } & Contrato & Data de Entrega \\
\hline 50013025 & EE Manoel da Costa Lima & $100 / 2008$ & $30 / 06 / 2009$ \\
\hline 50013033 & EE Peri Martins & $100 / 2008$ & $30 / 12 / 2008$ \\
\hline 50013050 & EE Professor Braz Sinigáglia & $100 / 2008$ & $30 / 06 / 2009$ \\
\hline 50024019 & EE Professor Luiz Alberto Abraham & $100 / 2008$ & $30 / 09 / 2009$ \\
\hline
\end{tabular}

Fonte: MEC/Sigetec.

Nota: $\mathrm{EE}=$ Escola Estadual.

As consultas ao Sistema de Gestão Tecnológica (Sigetec), detalhadas nos Quadros 2 e 3, indicam que as escolas estaduais de Bataguassu foram contempladas com todos os equipamentos previstos e necessários ao funcionamento das STEs.

A metodologia da pesquisa é descrita a seguir. 


\section{Metodologia da pesquisa}

Esta pesquisa possui como foco central de investigação a implantação e a implementação do Proinfo, sendo que o processo de implantação foi identificado e registrado a partir da consulta às bases de informação oficiais do Ministério da Educação (MEC), à legislação vigente e aos documentos oficiais do Estado de Mato Grosso do Sul. A implementação foi descrita considerando as percepções dos professores da rede pública estadual de ensino e dos docentes das STEs, que trabalham com turmas do $1^{\circ}$ ao $5^{\circ}$ ano do ensino fundamental, na zona urbana do município de Bataguassu.

Por se tratar de um grupo específico de pessoas e escolas, a investigação constitui-se em um estudo de caso (André, 2005, p. 17-18). Optou-se por uma pesquisa de abordagem qualitativa e quantitativa, pois, em concordância com Minayo (2001), considera-se que os aspectos qualitativos e quantitativos não se opõem, mas se complementam, sendo essenciais nos processos de pesquisa.

As origens do município campo da pesquisa - Bataguassu - datam de 1932, quando a Companhia Viação São Paulo-Mato Grosso, firma comercial de Jan Antonin Bata, fundador da Cidade, adquiriu uma gleba, desenvolveu a criação de gado e tentou a colonização em vários pontos, fixando-se, em 1941, na área em que se ergueu, posteriormente, a cidade de Bataguassu (Instituto..., 2010).

Bataguassu foi elevada à categoria de município por meio da Lei Estadual $n^{\circ}$ 683, de 11 de dezembro de 1953, desmembrando-se de Rio Brilhante e sendo constituído de quatro distritos: Bataguassu, Anaurilândia, Bataiporã e Ivinhema. Após inclusões e exclusões, desde 1979 é composto de dois distritos: Bataguassu e Porto XV de Novembro (Instituto..., 2010).

O município está situado às margens da rodovia BR-267, a 320 quilômetros da capital do Estado - Campo Grande. Sua dimensão territorial é de $2.415,297 \mathrm{Km}^{2}$ e sua população é de 19.839 habitantes, com densidade demográfica de 8,21 hab/ $\mathrm{Km}^{2}$ (Instituto..., 2010). ${ }^{2}$

Embora tenha sua base econômica no setor primário, com grande destaque para a pecuária, o Município, nos últimos anos, conta com crescimento no setor secundário, com a instalação de duas grandes indústrias, uma frigorífica e uma indústria e comércio de descartáveis e produtos domésticos e profissionais para festas e eventos. Ambas exportam para países da América Latina e para os Estados Unidos, a Europa, a Índia, a África e a Ásia. O Município possui outras indústrias de pequeno e médio porte nos setores de parafinas, lacticínios, enlatados e matérias plásticas (Bataguassu, 2013).

O desenvolvimento da pesquisa em questão se deu em três etapas,

${ }^{2}$ Os referidos dados são relativos à coleta com a data-base do ano de 2010, a mais recente pesquisa realizada pelo Instituto Brasileiro de Geografia e Estatística (IBGE) sendo que na primeira foi realizada a revisão bibliográfica a partir do tema, com levantamento nas seguintes bases de dados: Scientific Electronic Library Online (Scielo); sites públicos dos governos federal, estadual e municipal; e banco de teses e dissertações da Coordenação de 
Aperfeiçoamento de Pessoal de Nível Superior (Capes). No levantamento das fontes, foram utilizadas as seguintes palavras-chave ou descritores: Proinfo; Salas de Tecnologias Educacionais; uso das TICs na prática pedagógica; e rede estadual urbana de Bataguassu. Também foram usados livros sobre a temática. Procurou-se utilizar, primordialmente, materiais publicados nos últimos cinco anos.

No segundo momento relativo à pesquisa de campo, foram aplicados os instrumentos de coleta, abrangendo: um questionário com perguntas fechadas e abertas para os professores regentes do $1^{\circ}$ ao $5^{\circ}$ ano do ensino fundamental e um roteiro semiestruturado de entrevista (Laville; Dionne, 1999, p. 188) para os professores das STEs.

A população da pesquisa abrangeu $100 \%$ das escolas urbanas da rede estadual de ensino; $54 \%$ (16) dos professores do $1^{\circ}$ ao $5^{\circ}$ ano do ensino fundamental, do universo total de 30 profissionais; e 100\% (4) dos professores responsáveis pelas STEs, denominados na rede estadual de Professor Gerenciador de Tecnologias Educacionais e Recursos Midiáticos (PGTERM). O percentual de participantes representa o índice de adesão, já que os instrumentos e a solicitação de participação foram disponibilizados para $100 \%$ dos professores. A adesão à pesquisa se deu por meio da assinatura do Termo de Consentimento Livre e Esclarecido (TCLE).

Para garantir o anonimato dos professores respondentes da pesquisa, os questionários distribuídos foram codificados, adotando-se os seguintes critérios: a) para os professores regentes, foram utilizadas as siglas P1, P2 etc.; b) para os professores da STE, utilizaram-se PSTE1, PSTE2 etc.

\section{A percepção dos profissionais da educação de Bataguassu acerca do uso das TICs nas STEs}

Serão expostos a seguir o perfil dos profissionais sujeitos da pesquisa e a percepção que possuem sobre o processo de implementação do Proinfo em Bataguassu, iniciando-se com os professores regentes da rede estadual e, depois, com os Professores Gerenciadores de Tecnologias Educacionais e Recursos Midiáticos (PGTERMs), responsáveis pelas STEs.

\subsection{Professores regentes da rede estadual}

Os professores regentes pesquisados nas quatro escolas estaduais, que atuam na rede pública do município, são do sexo feminino (100\%), com predomínio na faixa etária de 41 a 50 anos (43\%). Os demais situam-se na faixa etária de 26 a 30 anos (19\%); 31 a 40 anos (19\%); e acima de 50 anos (19\%).

Não foi verificada disparidade significativa na faixa etária dos professores regentes das quatro escolas (Tabela 1), pois a maioria (81\%) situa-se na faixa acima de 31 anos, ou seja, pessoas experientes no âmbito pedagógico, mas nem sempre familiarizadas com as TICs, dadas a formação inicial e as práticas sociais locais. 
Tabela 1 - Faixas Etárias (em Anos) dos Professores, por Escola Pesquisada

\begin{tabular}{|l|c|c|c|c|c|}
\hline \multicolumn{1}{|c|}{ Escolas Estaduais } & $\mathbf{1 9 - 2 5}$ & $\mathbf{2 6 - 3 0}$ & $\mathbf{3 1 - 4 0}$ & $\mathbf{4 1 - 5 0}$ & $\begin{array}{c}\text { Acima } \\
\text { de 50 }\end{array}$ \\
\hline Professor Braz Sinigáglia & & & & 2 & 1 \\
\hline Professor Luiz A. Abraham & & & 1 & & 1 \\
\hline Manoel da C. Lima & & 2 & & 3 & 1 \\
\hline Peri Martins & & 1 & 2 & 2 & \\
\hline
\end{tabular}

Fonte: Questionários da pesquisa.

Quanto ao nível de escolaridade, todos os professores possuem nível superior e formação em Pedagogia, o que atende às metas estabelecidas no Plano Nacional de Educação (Brasil. Lei no 10.172, 2001).

Entre os professores regentes, 81\% possuem cursos de pós-graduação, sendo que 50\% em psicopedagogia e 31\% em diversas áreas (metodologia do ensino, educação profissional, avaliação, gestão educacional e pública, especialização em educação infantil e séries iniciais e pedagogia clínica e institucional).

A maioria dos docentes (75\%) atua há mais de dez anos na educação. Na data da coleta, 55\% dos professores indicaram trabalhar em apenas uma escola, enquanto o restante indicou trabalhar em duas escolas.

Quase a metade dos professores entrevistados possui carga horária superior a 40 horas semanais; observando o predomínio feminino, considera-se que essas professoras passam a maior parte do seu tempo na escola e se desdobram em segunda ou terceira jornada, nos afazeres domésticos. Sobre o assunto, Pereira e Zibetti (2010, p. 270) observam:

Esta sobrecarga evidencia aspectos culturais que se mantêm nas relações familiares, os quais levam as mulheres a assumirem as mesmas demandas que lhes eram atribuídas antes de ingressarem no mercado de trabalho. Mas também é consequência dos baixos salários recebidos pela categoria, pois enquanto outros/as profissionais mais bem remunerados/as encontram tempo livre para a família e o lazer por meio da contratação de mão de obra doméstica, as professoras não têm condições de fazer o mesmo.

Em relação à situação funcional dos professores, 69\% são efetivos do Estado e o restante é contratado, ou seja, a maioria dos professores possui estabilidade no trabalho.

Questionados sobre a utilização do computador no seu dia a dia, todos os docentes responderam que, de alguma forma, usam o computador em casa ou no trabalho.

A internet se constitui em uma ferramenta de uso comum e unânime entre os professores regentes pesquisados, em segundo lugar estão os editores de texto (87\%). As demais ferramentas somam apenas $13 \%$ das indicações de uso (Tabela 2). 
Tabela 2 - Ferramentas mais Utilizadas pelos Professores da Rede Estadual Urbana

\begin{tabular}{|l|c|c|c|c|c|c|}
\hline Ferramentas & $\begin{array}{c}\text { Braz } \\
\text { Sinigáglia }\end{array}$ & $\begin{array}{c}\text { Luiz A. } \\
\text { Abraham }\end{array}$ & $\begin{array}{c}\text { Manoel da } \\
\text { C. Lima }\end{array}$ & $\begin{array}{c}\text { Peri } \\
\text { Martins }\end{array}$ & Total & $\%$ \\
\hline Internet & 3 & 2 & 6 & 5 & 16 & 100 \\
\hline Editor de texto & 2 & 2 & 6 & 5 & 14 & 88 \\
\hline Planilhas & & 1 & & & 01 & 6,5 \\
\hline Outros & & & & 1 & 01 & 6,5 \\
\hline
\end{tabular}

Fonte: Questionários de pesquisa.

A seguir, informações sobre a formação dos professores regentes.

\subsubsection{Formação Inicial e Continuada sobre as TICs}

Em relação à participação dos professores regentes em cursos relacionados às TICs na escola, a pesquisa mostrou que a maioria (87\%) já participou de algum curso e 13\% não realizaram nenhum. Dentre esses cursos, os mais citados foram: Aprendendo com as TICs (19\%); Ambiente Linux (19\%); outros cursos (25\%), por exemplo, Planejamento Escolar, Introdução à Educação Digital, Elaboração de Projetos e Informática Básica. O restante dos professores (37\%) não lembrou ou não mencionou o nome do curso.

Segundo a avaliação dos docentes, os cursos auxiliam na elaboração das atividades e complementam a prática pedagógica. Porém, destaca-se o comentário de uma professora que considera negativo o resultado do curso sobre as TICs na escola, afirmando que: "o curso não tinha muito a ver com nosso dia a dia e prática pedagógica (P12)".

Quando questionados se foram capacitados com cursos oferecidos pela secretaria de educação para atuar nas STEs, 69\% dos professores regentes responderam que sim e 31\% responderam negativamente.

Em relação aos cursos realizados, as respostas foram bem variadas, sendo que 44\% mencionaram: Office, Elaboração de Projetos, Introdução à Educação Digital, Linux, Aprendendo com as TICs e Informática Básica. Para 25\% dos professores, não houve predomínio de nenhum curso específico e não houve comentários, por parte deles, acerca do curso realizado.

Uma das professoras disse que não havia realizado nenhum curso, esclarecendo: "já tenho conhecimento" (P13). Essa percepção é algo a ser destacado, principalmente na área tecnológica, campo marcado por uma constante mudança e aperfeiçoamento.

Ainda em relação à formação dos professores regentes, foi-lhes perguntado se a escola oferece cursos ou atividades para sua formação continuada referentes às TICs e às STEs, 87\% dos professores responderam positivamente e $13 \%$ responderam negativamente. 
Questionados sobre como é acompanhada essa formação continuada, preponderaram as seguintes respostas: testes e participação (25\%); por meio do professor da STE (13\%); outros 25\% foram respostas diversificadas e estão transcritas logo abaixo, pelas suas peculiaridades: "através de atividades e trabalhos online" (P1); "com cursos e nas aulas aplicando as TICs e a utilização da STE" (P8); "dá suporte pedagógico e tecnologia" (P9); "é aplicado na unidade escolar, ou seja, é desenvolvido um trabalho com os estudantes" (P12)

A seguir, dados sobre a utilização das STEs.

\subsubsection{Informações sobre a Sala de Tecnologia Educacional (STE)}

A média é de dois alunos por computador na maioria das escolas estaduais de Bataguassu (Tabela 3).

Tabela 3 - Quantidade de Aluno/Computador nas Escolas Pesquisadas

\begin{tabular}{|c|c|c|c|c|}
\hline Aluno/Computador & $\begin{array}{c}\text { Braz } \\
\text { Sinigáglia }\end{array}$ & $\begin{array}{c}\text { Luiz A. } \\
\text { Abraham }\end{array}$ & $\begin{array}{c}\text { Manoel da } \\
\text { C. Lima }\end{array}$ & $\begin{array}{c}\text { Peri } \\
\text { Martins }\end{array}$ \\
\hline 1 & & & $17 \%$ & $20 \%$ \\
\hline 2 & & $50 \%$ & $83 \%$ & $80 \%$ \\
\hline 3 & $100 \%$ & $50 \%$ & & \\
\hline
\end{tabular}

Fonte: Questionários de pesquisa.

Essa discrepância no número de alunos por computador provavelmente se deu pelo fato de que há salas de aula com diferentes números de discentes nas quatro escolas, sendo que a Professor Braz Sinigáglia possui maior número de alunos por computador, seguida da escola Professor Luiz A. Abraham.

Além do uso do computador não ser individual, o que dificulta a aprendizagem de todos, o espaço e a distribuição dos equipamentos também geram prejuízos ao atendimento dos estudantes. Embora não tenha sido objeto das questões, a observação direta nas escolas permitiu identificar uma organização espacial bastante inadequada. Como o espaço total da sala é muito pequeno, as máquinas ficam distribuídas ao redor das paredes (Figura 1), dificultando a explicação coletiva e o acompanhamento dos alunos. Embora essa organização seja indicada para melhor aproveitamento do espaço, o ideal seria um computador por aluno e a distribuição em fileiras, de modo que possibilitasse a visão do aluno às explicações dadas pelo professor (Figura 2). 


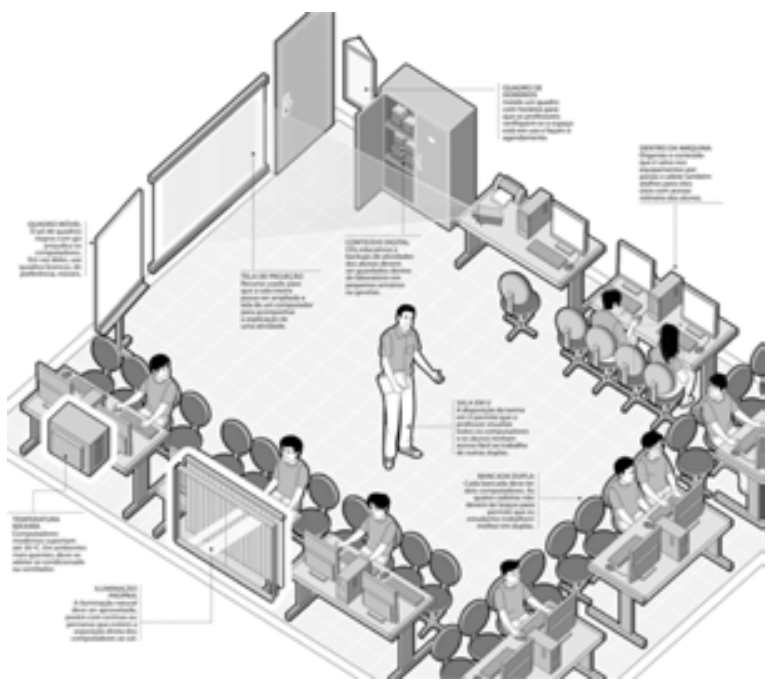

Figura 1 - Laboratórios das Salas de Tecnologias Educacionais Fonte: Rodrigues (2010).

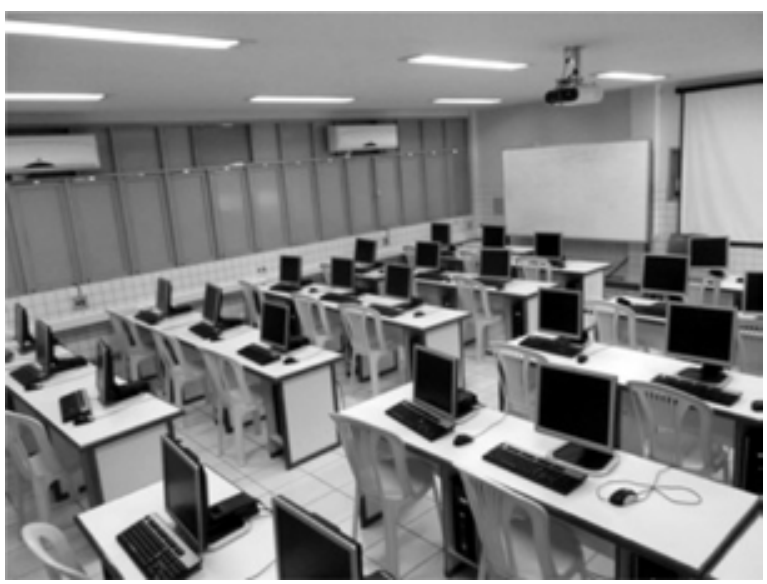

Figura 2 - Organização Espacial Desejável para as Salas de Tecnologias Educacionais

Fonte: UFRN (2013).

Quanto ao horário de utilização da STE, todas as respostas dos professores regentes convergiram, mostrando que a sala é disponibilizada de forma sistematizada, com agendamento prévio junto ao Professor Gerenciador de Tecnologias Educacionais e Recursos Midiáticos (PGTERM).

Sobre o funcionamento das STEs, a Resolução/SED no 2.491/2001 diz, no Capítulo II, que:

Art. 10 O horário de atendimento das STEs obedecerá aos turnos de funcionamento, ao calendário escolar, ao projeto político-pedagógico e ao planejamento dos professores.

Art. 11 A utilização pedagógica das tecnologias educacionais e recursos midiáticos basear-se-á: 
I - nos referenciais curriculares da rede estadual de ensino;

II - no projeto político-pedagógico da escola. (Mato Grosso do Sul, 2011, p. 14).

Em relação ao planejamento das atividades desenvolvidas nas STEs, existe um consenso entre os professores regentes. Eles afirmaram que existe uma soma de fatores para a programação das atividades, tais como: o referencial curricular e os conteúdos das aulas; o auxílio dos coordenadores; o auxílio dos PGTERMs e o próprio planejamento online da SED.

Quando questionados se e de que maneira os docentes das STEs participam das aulas propostas nesse ambiente, 88\% dos professores regentes relataram que participam e 12\% disseram que não. Desses 88\% que responderam positivamente, $63 \%$ afirmaram que os auxiliam com sugestões; 6\% somente com auxílio técnico (ligar e desligar o computador); e 19\% não se manifestaram.

A afirmação dos professores é coerente com a Resolução/SED $n^{\circ}$ 2.491/2011:

Art. 14. Caberá ao professor responsável pelo gerenciamento das tecnologias educacionais e recursos midiáticos nas unidades escolares:

I - auxiliar os professores regentes no planejamento e desenvolvimento das atividades pedagógicas no uso das tecnologias educacionais;

III - responsabilizar-se pelo gerenciamento das tecnologias educacionais e recursos midiáticos, juntamente com a direção e coordenação pedagógica da unidade escolar, em conformidade com o projeto político-pedagógico, referenciais curriculares da rede estadual de ensino;

IV - apresentar aos professores regentes sugestões do uso das tecnologias e mídias para a melhoria do processo de ensino e aprendizagem. (Mato Grosso do Sul, 2011, p. 14).

O comentário de uma das professoras regentes vai na contramão das demais observações, quando afirma: "às vezes, porque o governo não quer a presença do mesmo na sala (STE) durante nossas aulas, algo que acho horrível e gostaria que a mesma permanecesse na STE" (P15).

A Tabela 4 contém alguns indicadores da prática pedagógica nas escolas participantes da pesquisa.

Os dados da Tabela 4 indicam percepção positiva quanto à prática pedagógica das referidas escolas, exceto sobre o uso da internet nas aulas, pois $50 \%$ dos professores regentes a utilizam com os alunos somente para pesquisas e outros $50 \%$ a utilizam de maneira mais versátil, aplicando melhor as suas ferramentas.

Indezeichak (2007, p. 3, grifo nosso) ressalta a necessidade premente de atualização constante do professor em relação à internet:

Muitos professores não sabem usar o computador, portanto, a primeira medida a se tomar é aprender a fazer isso. É preciso dominar o que este recurso pode fazer, para depois saber o que fazer com ele. É preciso, pelo menos, ter intimidade com os editores de textos, apresentações de 
slides, entre outros tantos, bem como estar apto para usar a Internet. A Internet e as novas tecnologias estão trazendo novos desafios pedagógicos para as escolas. Os professores precisam utilizá-las de forma equilibrada e inovadora. (Indezeichak, 2007, p. 3, grifo nosso)

\section{Tabela 4 - Indicadores das Práticas Pedagógicas na STE nas Escolas Pesquisadas}

\begin{tabular}{|c|c|c|c|c|c|c|c|c|c|c|}
\hline \multirow[b]{2}{*}{ Indicadores } & \multicolumn{2}{|c|}{$\begin{array}{c}\text { Braz } \\
\text { Sinigáglia }\end{array}$} & \multicolumn{2}{|c|}{$\begin{array}{l}\text { Luiz A. } \\
\text { Abraham }\end{array}$} & \multicolumn{2}{|c|}{$\begin{array}{l}\text { Manoel da } \\
\text { C. Lima }\end{array}$} & \multicolumn{2}{|c|}{$\begin{array}{c}\text { Peri } \\
\text { Martins }\end{array}$} & \multicolumn{2}{|c|}{ Total } \\
\hline & Sim & Não & Sim & Não & Sim & Não & Sim & Não & Sim & Não \\
\hline $\begin{array}{l}\text { Utiliza internet somente para } \\
\text { pesquisa }\end{array}$ & 3 & & 1 & 1 & 2 & 4 & 2 & 3 & 8 & 8 \\
\hline $\begin{array}{l}\text { Emprega softwares educativos } \\
\text { nas aulas }\end{array}$ & 3 & & 2 & & 6 & & 5 & & 16 & \\
\hline $\begin{array}{l}\text { Conhece algum software } \\
\text { educativo }\end{array}$ & 3 & & 2 & & 6 & & 5 & & 16 & \\
\hline $\begin{array}{l}\text { Os alunos demonstram interesse } \\
\text { nas aulas na STE }\end{array}$ & 3 & & 2 & & 6 & & 5 & & 16 & \\
\hline $\begin{array}{l}\text { Os alunos são participativos e } \\
\text { constantes }\end{array}$ & 3 & & 2 & & 6 & & 5 & & 16 & \\
\hline Mostram-se desinteressados & & 3 & & 2 & & 6 & & 5 & & 16 \\
\hline $\begin{array}{l}\text { Você abre espaço para as ideias } \\
\text { dos alunos }\end{array}$ & 3 & & 2 & & 6 & & 5 & & 16 & \\
\hline $\begin{array}{l}\text { Você ou a escola realiza projetos } \\
\text { na STE }\end{array}$ & 3 & & 2 & & 6 & & 5 & & 16 & \\
\hline
\end{tabular}

Fonte: Questionários de pesquisa.

Observa-se que há certa contradição de alguns professores ao considerarem positivos todos os indicadores, haja vista que, em algumas questões anteriores, alguns docentes afirmaram não estar capacitados para atuar na STE.

Quando questionados sobre a aprendizagem dos alunos na STE, mais de 50\% dos professores regentes a consideraram suficiente (Gráfico 1).

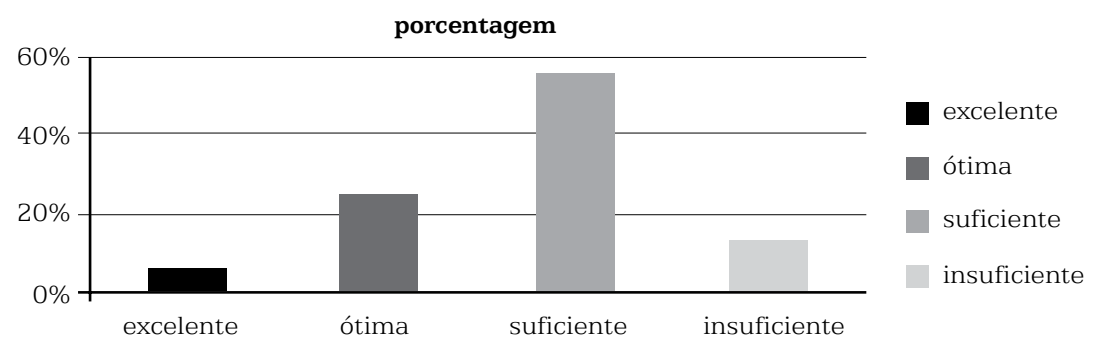

Gráfico 1 - Indicadores da Aprendizagem dos Alunos na STE

Fonte: Questionários da pesquisa.

Na segunda parte da questão, foi solicitado que os professores justificassem suas respostas, 56\% deles concordam que a STE auxilia na aprendizagem dos alunos, 31\% não justificaram sua resposta e 13\% 
responderam negativamente, observando: "insuficiente no que depender da tecnologia. Os alunos não conseguem trabalhar sozinhos" (P5). "Porque muitas vezes não está de acordo com nossas expectativas" (P7).

Tais afirmações apontam para a percepção do professor que se ausenta de seu papel de mediador no processo. Outro aspecto a ser observado é que muitos docentes têm menos habilidades para trabalhar nos computadores do que os próprios alunos, esperando autonomia deles para operar as máquinas e realizar atividades.

Valente (1998, p. 2) aborda sobre o assunto:

Assim concebido, o computador é uma ferramenta que pode auxiliar o professor a promover aprendizagem, autonomia, criticidade e criatividade do aluno. Mas, para que isto aconteça, é necessário que o professor assuma o papel de mediador da interação entre aluno, conhecimento e computador, o que supõe formação para exercício deste papel. Nem sempre é isto, entretanto, que se observa na prática escolar.

Posteriormente, os professores regentes foram questionados sobre a motivação e o comportamento dos alunos no ambiente da STE, 87\% responderam que os alunos têm um comportamento adequado e se mostram interessados, já que a aula ocorre em outro ambiente. Entretanto, $13 \%$ responderam que os alunos são indisciplinados e somente querem brincar em frente ao computador.

Quanto aos fatores que facilitam e os que dificultam o desenvolvimento do professor na interação da STE à sua prática pedagógica, as respostas foram bem diversificadas, mostrando certo descontentamento dos docentes e incidência maior de fatores negativos do que de positivos. Entre os aspectos positivos, destacam-se: a aprendizagem do aluno, indicada por 31\% dos professores; o auxílio do PGTERM, apontado por 37\%; e outros fatores, como os bons sites de pesquisa, os trabalhos em duplas e a melhora do interesse do aluno, que somaram juntos a indicação de 32\%.

Os fatores que dificultam, na percepção dos professores, são os seguintes: poucos computadores (38\%); indisciplina (19\%); e falta de interesse do aluno, de tempo para pesquisa, de habilidade no computador, de auxílio do professor da STE, de manutenção das máquinas (43\%).

Os professores regentes foram indagados se, de fato, acreditavam que a STE os auxiliava no processo de aprendizagem de seus alunos ou, simplesmente, se a utilizavam por fazer parte do planejamento das escolas e $94 \%$ responderam que de fato percebem a STE como dispositivo de auxílio no processo de ensino, o que é expresso nos comentários: "os recursos midiáticos são importantes para ampliar as possibilidades de aprendizagem, porém, o computador não atinge o objetivo, pois são poucos momentos e poucas máquinas" (P2). "Utilizo por acreditar e ver que realmente quando levados a STE com "objetivo" auxilia sim no processo de aprendizagem do aluno (sic)" (P15).

Esse dado mostra que os professores, mesmo tendo algumas dificuldades em relação às novas tecnologias, acreditam que elas podem auxiliar de alguma forma o processo de aprendizagem dos alunos. 
Quanto à importância e validade do ensino nas STEs, os professores consideram que:

a) as STEs facilitam o processo de aprendizagem dos alunos (31\%);

b) os docentes desenvolvem novas práticas pedagógicas (19\%);

c) os alunos aprendem de maneira mais prazerosa, pois a inclusão digital ajuda o professor na apresentação de conteúdos e aulas diferenciadas e lúdicas (31\%);

d) abstenções (19\%).

Os resultados indicam que as STEs são importantes na escola, na percepção dos professores, mas também apontam falhas no seu uso pedagógico.

Cada vez mais o ambiente de aprendizagem informatizado ganha espaço nas escolas, contudo, para que se tenha bom aproveitamento das atividades a serem desenvolvidas nas STEs, é fundamental que sejam planejadas e estejam condizentes com o que está sendo desenvolvido nas aulas.

\subsection{Professor Gerenciador de Tecnologias Educacionais e Recursos Midiáticos (PGTERM)}

Dos PGTERMs pesquisados nas quatro escolas estaduais, que atuam nas STEs da rede estadual do município de Bataguassu, 25\% estão na faixa etária de 19 a 25 anos; 50\%, de 26 a 30 anos; e 25\%, de 31 a 40 anos. Sendo $25 \%$ do sexo masculino e $75 \%$ do feminino.

Quanto à formação lato sensu, 50\% dos PGTERMs possuem pósgraduação (Educação Especial e Psicopedagogia).

Em relação ao tempo de atuação nas STEs, 50\% dos professores atuam na função de PGTERMs mais recentemente (de 1 a 3 anos); 25\%, de 4 a 6 anos; e 25\% atuam há mais tempo, de 7 a 9 anos (Gráfico 2).

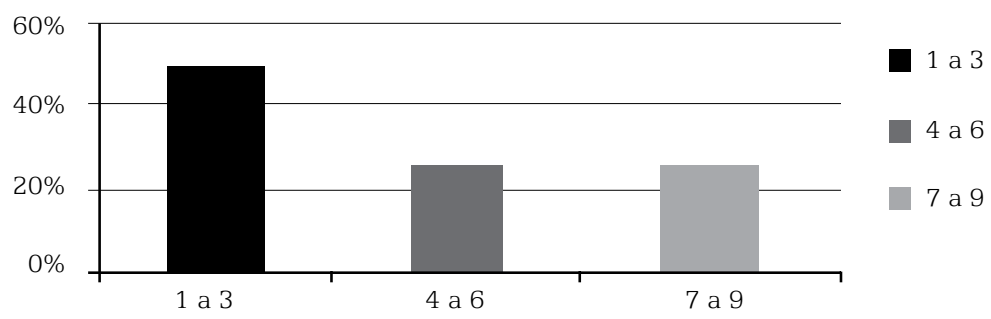

\section{Gráfico 2 - Tempo de Atuação dos Professores Gerenciadores na Sala de Tecnologia Educacional}

Fonte: Entrevista da pesquisa.

Quanto à formação profissional dos professores, foi constatado que todos possuem capacitação com diversos cursos vinculados ao Proinfo, destacando-se os relacionados à educação: Introdução à Educação Digital 
(100\%); Aprendendo e Ensinando com as TICs (75\%); Ação de Planejar no Interior da Escola (75\%); Elaboração de Projetos (75\%); Mídias na Educação (50\%); e Tecnologia na Educação Escolar (50\%). Ressalta-se que os professores têm outros cursos relacionados às tecnologias em seus currículos.

Questionados quanto à avaliação dessa formação do Proinfo, todos os docentes foram bem positivos, dizendo que a capacitação é de grande importância para o desenvolvimento das atividades nas STEs.

Perguntados sobre a participação da SED/MS na formação dos professores com as TICs, $100 \%$ dos entrevistados disseram ser ótima, oferecendo incentivo ao processo de ensino e aprendizagem com os cursos de capacitação.

\subsubsection{As TICs na Escola e o Funcionamento da STE}

Questionados sobre as políticas nacionais e estaduais para o uso das TICs e como as avaliavam, 75\% dos entrevistados responderam que as conhecem e 25\% não responderam. Contudo, somente $50 \%$ dos professores fizeram uma avaliação, de forma superficial, destacando-se os comentários a seguir: "Sim, são relevantes e essenciais" (PSTE3). "Sim, as TICs contribuíram para a efetividade do processo de ensino e aprendizagem" (PSTE4).

Quando perguntados por qual motivo escolheram atuar na STE, 50\% dos professores disseram que foi o interesse em aprender sobre novas tecnologias, 25\% destacaram a oportunidade de emprego e possibilidade de aprender e somente $25 \%$ apontaram o interesse em colocar as tecnologias em favor do ensino, destacando-se o seguinte comentário: "habilidade com as tecnologias e o prazer de colocá-las no processo de ensino-aprendizagem" (PSTE3).

Quanto à preparação dos professores regentes para o uso das TICs, 100\% dos PGTERMs destacaram que eles precisam realizar mais cursos disponibilizados pelos órgãos de educação e afirmaram que alguns professores ainda demonstram alguma resistência quanto ao uso de tais tecnologias, contudo, ressaltaram que houve uma melhora significativa, pois alguns professores têm demonstrado mais interesse pelas TICs.

Um dos professores salientou que "alguns ainda estão resistentes ao uso das TICs, pois possuem pouco conhecimento e relutam em se aperfeiçoarem, porém, outros têm total domínio" (PSTE1).

Questionados se e de que maneira a escola dá suporte para os trabalhos desenvolvidos nas STEs, 75\% responderam que sim, disponibilizando os materiais necessários, auxiliando e dando liberdade, principalmente, no desenvolvimento e na criação de projetos. Entretanto, 25\% disseram que a escola não auxilia e que é o NTE que fornece cursos durante todo o ano e faz o monitoramento da STE.

Quanto à organização para o uso da STE, 100\% afirmaram que o horário é sistematizado com agendamento antecipado, compactuando com as respostas dos professores regentes. 
Perguntados sobre a quantidade de computadores por aluno e se é suficiente para as atividades desenvolvidas e para a aprendizagem, 75\% disseram que a média é de dois alunos por computador, concordando com as respostas dos professores regentes, e que a quantidade é suficiente para as atividades e para a aprendizagem; apenas a PSTE1 destacou que na escola em que atua a média é de três alunos por computador.

Sobre a rotina e o planejamento das atividades ocorridas na STE, os professores deram respostas bem convergentes, dizendo que fazem o agendamento das aulas segundo o diário online, acompanhando e auxiliando o planejamento dos professores regentes, informando-os sobre cursos e capacitações e zelando pela STE.

A qualidade da interação com os professores regentes é considerada boa por 50\% dos PGTERMs, sendo que 25\% consideram adequada e os outros 25\%, ótima.

Quando questionados sobre a resistência dos professores regentes quanto ao uso das TICs, 75\% dos entrevistados disseram que não havia resistência, entrando em contradição com respostas da questão anterior, quando mencionaram que alguns professores não buscavam melhorar seu conhecimento em relação às TICs por ainda resistirem às tecnologias. Somente 25\% dos PGTERMs disseram que havia resistência de alguns professores em relação ao uso dessas ferramentas.

Perguntados como avaliavam a motivação e o comportamento do aluno na STE, 100\% responderam positivamente: "da melhor maneira possível. Uma aula na STE muda totalmente o comprometimento e até combate a indisciplina, porque o aluno interage muito mais" (PSTE3). "Eles se sentem motivados, pois há possibilidades de novos saberes, permitindo que os estudantes explorem outras formas de conhecimento, uma vez que já nasceram na era das tecnologias" (PSTE4).

Questionados sobre os fatores que facilitavam ou dificultavam a integração das TICs à prática pedagógica dos professores nas escolas que atuam, 50\% disseram que o fator que facilitava eram os recursos tecnológicos, porém, um dos PGTERMs relatou que a quantidade desses recursos era fator dificultador, assim como a falta de interesse dos próprios docentes, evidenciado por outro professor gerenciador.

A "hora atividade"3 foi destacada, por outro docente, como fator facilitador, e o dificultador também era a falta de interesse dos professores; outro não respondeu à pergunta.

Nota-se que a metade dos entrevistados acredita que as ferramentas tecnológicas podem ser utilizadas como fim e não como meio no tocante às práticas pedagógicas, incidindo num equívoco comum, como explica Valente (2003, p. 15):

[...] muitos educadores ainda não sabem o que fazer com os recursos que a informática oferece. E, nesse sentido, a chave do problema é a questão da formação, da preparação dos educadores para saberem como utilizar esta ferramenta como parte das atividades que realizam na escola.

\footnotetext{
${ }^{3}$ Lei no $11.738 / 2008-$ art. $2^{\circ}$, em que um terço da carga horária deve ser dedicado à preparação de aulas e às demais atividades fora da sala.
} 
Questionados se as atividades desenvolvidas sob a supervisão deles nas STEs cumpriam os objetivos do Proinfo, 100\% dos entrevistados responderam positivamente.

Foi-lhes perguntado, ao final, sobre a importância e a validade do ensino no ambiente da STE e todos indicaram percebê-las:

"Acho que a STE é mais uma ferramenta pedagógica que o docente poderá utilizar para melhorar suas práticas" (PSTE1).

"Nos dias de hoje, sempre temos que estar por dentro das tecnologias" (PSTE2).

"De fundamental importância, um instrumento revolucionário no processo de ensino-aprendizagem" (PSTE3).

"A sala de tecnologias é um ambiente construtivo, dando a oportunidade de inserir o estudante na era tecnológica, aprimorando seus conhecimentos e abrindo novos horizontes, desenvolvendo a consciência de pesquisador" (PSTE4).

Dados os comentários dos PGTERMs, notamos que 50\% acentuam a importância da STE para o ensino, mas não explicam de forma clara como isso é possível. Os outros 50\% acreditam que a STE é simplesmente um dispositivo para inserir o aluno no mundo das tecnologias e, também, um mero instrumento de pesquisa.

\section{Considerações finais}

Com exceção do uso da internet, os indicadores avaliados pelos professores regentes apontaram para uma prática pedagógica na STE quase perfeita, na qual alunos e professores teriam comportamento ideal em quesitos centrais para atividades naquele ambiente. No entanto, esses indicadores divergem da afirmação dos PGTERMs, que dizem que a maioria dos professores não está preparada para lidar com as TICs nas práticas desenvolvidas na STE.

A descontinuidade da forma de gestão das STEs e do papel dos profissionais responsáveis, que são atualmente definidos no Estado de Mato Grosso do Sul como gerentes de tecnologia, é manifestada nos resultados da pesquisa. Essa percepção se choca com as orientações do Proinfo, que pontuam a atuação dos responsáveis pelas STEs também em uma dimensão didático-pedagógica, no sentido de auxiliar os professores regentes no planejamento e na execução das aulas que ali ocorrem.

Entre os fatores positivos, destaca-se o fato de que $87 \%$ dos professores regentes e $100 \%$ dos professores da STE consideram que a motivação e o comportamento dos alunos melhoram muito no ambiente da STE.

Observa-se que tanto os professores regentes quanto os PGTERMs acham importante o uso das TICs na escola. Alguns acreditam que auxiliam na prática pedagógica e na aprendizagem, outros, que o objetivo é inserir alunos e professores no mundo tecnológico. Observa-se, assim, 
que há clareza da importância e validade do ensino na STE como meio de acesso às TICs, mas não exatamente como mediador do processo de ensino e aprendizagem, o que implicará ampliação e melhoria da formação continuada desses docentes.

Valente (2005, p. 30) vem ao encontro dessa ideia quando afirma:

\begin{abstract}
A formação do professor deve prover condições para que ele construa conhecimento sobre as técnicas computacionais, entenda por que e como integrar o computador na sua prática pedagógica e seja capaz de superar barreiras de ordem administrativa e pedagógica. Essa prática possibilita a transição de um sistema fragmentado de ensino para uma abordagem integradora de conteúdo e voltada para a resolução de problemas específicos do interesse de cada aluno. Finalmente, deve-se criar condições para que o professor saiba recontextualizar o aprendizado e a experiência vivida durante a sua formação para a sua realidade de sala de aula compatibilizando as necessidades de seus alunos e os objetivos pedagógicos que se dispõe a atingir.
\end{abstract}

Os dados da pesquisa revelam que, embora a maioria dos professores conheça as TICs e saiba da sua importância para o ensino, eles não possuem preparo adequado para esse processo, realizando cursos aleatórios, fragmentando, dessa forma, sua formação continuada. Outro fator a ser destacado é que pelo menos 50\% dos PGTERMs não concebem o real valor desse ambiente para o ensino e, muito embora tenham conhecimento na área tecnológica, não conseguem relacionar as TICs às práticas pedagógicas com a coerência necessária para auxiliar os professores regentes de forma apropriada nas atividades estabelecidas para as STEs.

Observa-se neste locus particular - a rede estadual de Bataguassu - a presença das políticas públicas, induzidas pela União, que buscam implementar as tecnologias nas instituições de ensino dos estados e municípios com a inserção de máquinas e oferta de cursos de formação continuada. As STEs foram e estão sendo implantadas nessas escolas, mas os resultados deste estudo indicam que isso não é o bastante. São necessárias mudanças de paradigmas, de conceitos, que passam pelas condições efetivas de trabalho e de formação continuada que não se dê como fardo aos professores já sobrecarregados. Por exemplo, não é eficaz a oferta de cursos nos finais de semana para docentes que atuam dois ou três turnos nas escolas e se desdobram em outras atividades necessárias à sua subsistência.

Tais mudanças devem priorizar especialmente a formação continuada dos professores, mas, primeiramente, deve haver um trabalho de conscientização a respeito dessas novas práticas de ensino, ou seja, o professor precisa entender o motivo pelo qual é importante utilizar as STEs, nesse caso específico. Segundo Cysneiros (1998), muitos professores utilizam o computador de maneira tão rudimentar para algumas atividades, que tais tarefas poderiam ser realizadas com equipamentos mais simples.

O professor precisa mudar essa cultura de usar o computador apenas para pesquisar trabalhos na internet, preparar slides no power point 
etc. Tais ações remetem a uma perspectiva tradicional do ensino muito diferente do uso proposto pelas diretrizes educacionais. Diretrizes essas que preconizam que o uso do computador possibilitará ao professor criar ambientes de aprendizagem que privilegiam a construção do conhecimento pelos próprios alunos.

Os dados e informações obtidos nesta pesquisa indicam a necessidade de uma conjunção de vários fatores para que se possa garantir a eficácia das políticas públicas no chão da escola, dada a consciência de que a concretização desses fatores demanda tempo, investimentos, avaliação e reavaliação. Vale salientar a necessidade premente da elaboração de políticas que permitam a efetividade das ações e a concretização de objetivos, pois investimentos parciais, com planejamento inexequível, centrados na máxima exploração dos trabalhadores no âmbito da educação, tornam-se muito mais caros ao poder público. Contudo, a gravidade maior reside no custo social, pois a ineficácia da ação pública persiste na esfera educacional, especialmente num mundo globalizado, e tem preço incalculável a ser cobrado num futuro próximo.

\section{Referências bibliográficas}

ANDRÉ, M. E. D. A. Estudo de caso: conceito e fundamentos. In: . Estudo de caso em pesquisa e avaliação educacional. Brasília: Liber Livro, 2005. p. 13-22.

ARAÚJO, T. M. de et al. Diferenciais de gênero no trabalho docente e repercussões sobre a saúde. Ciência e Saúde Coletiva, Rio de Janeiro, v.11, n. 4, p.1117-1129, 2006.

BATAGUASSU. Prefeitura Municipal: histórico. Disponível em: <www. bataguassu.ms.gov.br > . Acesso em: 15 fev. 2013.

BRASIL. Conselho Nacional de Educação (CNE). Conselho Pleno (CP). Resolução CNE/CP n 01, de 15 de maio de 2006. Institui as Diretrizes Curriculares Nacionais para o Curso de Pedagogia - Licenciatura. Diário Oficial da União, Brasília, DF, 16 maio 2006. Seção 1, p. 11. Disponível em: < http://portal.mec.gov.br/cne/arquivos/pdf/rcp01_06.pdf>. Acesso em: 28 maio 2013.

BRASIL. Conselho Nacional de Educação (CNE). Conselho Pleno (CP). Resolução CNE/CP nº 1, de 18 de fevereiro de 2002. Institui Diretrizes Curriculares Nacionais para a Formação de Professores da Educação Básica, em nível superior, curso de licenciatura, de graduação plena. Diário Oficial da União, Brasília, DF, 9 abr. 2002. Seção 1, p. 31. 
BRASIL. Ministério da Educação (MEC). Decreto n 6.300, de 12 de dezembro de 2007. Dispõe sobre o Programa Nacional de Tecnologia Educacional - Proinfo. Diário Oficial da União, Brasília, DF, 2007. Disponível em:<http://gestao2010.mec.gov.br/marcos_legais/ decree_19.php>. Acesso: 28 jun. 2012.

BRASIL. Ministério da Educação (MEC). Portaria no 522, de 09 de abril de 1997. Criado o Programa Nacional de Informática na Educação - Proinfo. Diário Oficial da União, Brasília, DF, 11 abr. 1997. Seção 1, p. 7.189. Disponível em:<http://portal.mec.gov.br/index. php?option $=$ com_content\&view $=$ article\&id $=236 \&$ Itemid $=471>$. Acesso em: 28 jun. 2012.

BRASIL. Ministério da Educação (MEC). Sistema de gestão tecnológica: relatório distribuição por programa e contrato: Proinfo: consulta. Brasília, DF. Disponível em: < http://sip.Proinfo.mec.gov.br/ sisseed_fra. php>. Acesso em: 13 fev. 2013.

BRASIL. Lei no 9.394, de 20 de dezembro de 1996. Estabelece as diretrizes e bases da educação nacional. Diário Oficial da União, Brasília, DF, 23 dez. 1996. Disponível em: <http://www.planalto.gov.br/ ccivil_03/leis/19394.htm>. Acesso em: 18 mar. 2013.

BRASIL. Lei no 10.172, de 9 de janeiro de 2001. Aprova o Plano Nacional de Educação e dá outras providências. Diário Oficial da União, Brasília, DF, 10 jan. 2001. Disponível em: <http://www.planalto.gov.br/ ccivil_03/Leis/LEIS_2001/L10172.htm>. Acesso em: 22 abr. 2013.

BRASIL. Lei no 11.738, 16 de julho de 2008. Regulamenta a alínea "e" do inciso III do caput do art. 60 do Ato das Disposições Constitucionais Transitórias, para instituir o piso salarial profissional nacional para os profissionais do magistério público da educação básica. Diário Oficial da União, Brasília, DF, 17 jul. 2008. Disponível em: < http://www. planalto.gov.br/ccivil_03/_ato2007-2010/2008/lei/111738.htm>.

CYSNEIROS, P. G. Novas tecnologias na sala de aula: melhoria do ensino ou inovação conservadora? Informática Educativa, Bogotá, v. 12, n. 1, p. 11-24, 1999.

INDEZEICHAK, S. T. O professor de língua portuguesa e o ensino mediado pela tecnologia. Ponta Grossa: Universidade Estadual de Ponta Grossa, 2007. p. 1-29. Disponível em: <http://www.diaadiaeducacao. pr.gov.br/portals/pde/arquivos/19-4.pdf>. Acesso em: 29 jun. 2013.

\section{INSTITUTO BRASILEIRO DE GEOGRAFIA E ESTATÍSTICA (IBGE).}

Cidades@: consulta data-base 2010. Bataguassu, MS. Disponível em: <http://www.ibge.gov.br/cidadesat/topwindow.htm?1>. Acesso em:

15 Fev. 2013. 
LAVILLE, Christian; DIONNE, Jean. A construção do saber: manual de metodologia da pesquisa em ciências humanas. Belo Horizonte: UFMG, 1999.

MATO GROSSO DO SUL. Secretaria de Estado de Educação (SED). Projeto Estadual de Informática na Educação. Campo Grande, MS: [s.n.], 1997.

MATO GROSSO DO SUL. Decreto n 9.271, de 17 de dezembro de 1998. Cria os Núcleos de Tecnologia Educacional que menciona, e da outras providências. Diário Oficial da União, 18 dez. 1998.

MATO GROSSO DO SUL. Decreto n ${ }^{\circ} 9.271$, de 17 de dezembro de 1998. Extingue o Centro de Informática Educacional, com sede no município de Campo Grande, e dá outras providências. Diário Oficial [do] Estado do Mato Grosso do Sul, Campo Grande, 18 dez. 1998. n. 4921, p. 2.

MATO GROSSO DO SUL. Decreto n ${ }^{\circ} 12.437$, de 31 de outubro de 2007. Reorganiza os Núcleos de Tecnologia Educacional, no âmbito da Secretaria de Estado de Educação, e dá outras providências. Diário Oficial [do] Estado do Mato Grosso do Sul, Campo Grande, 1 nov. 2007. p. 2.

MATO GROSSO DO SUL. Decreto no 13.421, de 18 de maio de 2012. Reorganiza os Núcleos de Tecnologia Educacional, no âmbito da Secretaria de Estado de Educação, e dá outras providências. Diário Oficial [do] Estado do Mato Grosso do Sul, Campo Grande, 21 maio 2012. p. 6.

MATO GROSSO DO SUL. Secretaria de Estado de Educação (SED). Projeto Estadual de Informática na Educação. Campo Grande, MS: 1997.

MATO GROSSO DO SUL. Secretaria de Estado de Educação (SED). Resolução SED/MS n 1.570, de 4 de setembro de 2002. Dispõe sobre a lotação e atribuições de professor da educação básica para exercer a função de professor em sala de informática nas unidades escolares da rede estadual de ensino, e dá outras providências. Diário Oficial [do] Estado do Mato Grosso do Sul, Campo Grande, 5 set. 2002. n. 5830, p. 7.

MATO GROSSO DO SUL. Secretaria de Estado de Educação (SED). Resolução SED/MS n 1.842, de 8 de abril de 2005. Revoga a Resolução SED/MS n ${ }^{\circ} 1.570 / 2002$. Dispõe sobre a criação das Salas de Tecnologias Educacionais, a lotação e atribuições de professor da educação básica 
para exercer a função de professor regente nessas salas nas unidades escolares da rede estadual de ensino, e dá outras providências. Diário Oficial [do] Estado do Mato Grosso do Sul, Campo Grande, 11 abr. 2005. n. 6463, p. 12.

MATO GROSSO DO SUL. Secretaria de Estado de Educação (SED). Resolução SED/MS n ${ }^{\circ} 2.127$, de 5 de junho de 2007. Revoga a Resolução SED/MS n 1.842/2005. Dispõe sobre a implantação, implementação, monitoramento e avaliação das Salas de Tecnologias Educacionais na rede estadual de ensino, e dá outras providências. Diário Oficial [do] Estado do Mato Grosso do Sul, Campo Grande, 5 jun. 2007. n. 6984, p. 17.

MATO GROSSO DO SUL. Secretaria de Estado de Educação (SED). Resolução SED/MS n².491, de 8 de dezembro de 2011. Revoga a Resolução SED/MS n 2.127, de 5 de junho de 2007. Dispõe sobre o Projeto de implementação das Salas de Tecnologias Educacionais (STEs) e a utilização das diversas tecnologias midiáticas nas unidades escolares da rede estadual de ensino, e dá outras providências. Diário Oficial [do] Estado do Mato Grosso do Sul, Campo Grande, 9 dez. 2011. n. 8085, p. 14.

MINAYO, M. C. Pesquisa social: teoria, método e criatividade.

Petrópolis: Vozes, 1994.

MINAYO, M. C. Ciência, técnica e arte: o desafio da pesquisa social. In: _ (Org.). Pesquisa social: teoria, método e criatividade.

19. ed. Petrópolis: Vozes, 2001. p. 9-30.

PENTEADO, M. G. Redes de trabalho: expansão das possibilidades da informática na educação matemática da escola básica. In: BICUDO, M. A. V.; BORBA, M. C. (Org.). Educação Matemática: pesquisa em movimento. 2 ed. São Paulo: Cortez, 2005. p. 283-295.

PEREIRA, S.R; ZIBETTI, M. L. T. Mulheres e professoras: repercussões da dupla jornada nas condições de vida e no trabalho docente. Educar em Revista, Curitiba, n. 2, p. 259-276, 2010.

RODRIGUES, Cinthia. Como montar o laboratório de informática e fazer uma boa gestão do espaço. Nova Escola, São Paulo, n. 6, fev./ mar. 2010. Disponível em: <http://revistaescola.abril.com.br/gestaoescolar/diretor/como-montar-laboratorio-informatica-tecnologiacomputadores-539180.shtml>. Acesso em: 12 jul. 2013.

SAVIANI, Dermeval. Pedagogia histórico-crítica: primeiras aproximações. 8. ed. Campinas, SP: Autores Associados, 2003. 
UNIVERSIDADE FEDERAL DO RIO GRANDE DO NORTE (UFRN).

Descrição da infraestrutura dos laboratórios. Disponível em: < http:// www3.ifrn.edu.br/ infolabs-mo/wordpress/?page_id=20>. Acesso em: 10 jul. 2013.

VALENTE, J. A. (Org.). O computador na sociedade do conhecimento. Campinas, SP: NIED/Unicamp, 1999.

VALENTE, J. A. Formação de educadores para o uso da informática na escola. Campinas: NIED/Unicamp, 2003.

VALENTE, J. A. Formação de profissionais na área de Informática em Educação. In: (Org.). Computadores e conhecimento: repensando a educação. 2. ed. Campinas, SP: NIED/Unicamp, 1998.

VALENTE, J. A. Pesquisa, comunicação e aprendizagem com o computador... o papel do computador no processo ensinoaprendizagem. In: ALMEIDA, M. E. B. de; MORAN, José Manuel. Integração das tecnologias na educação. Brasília, DF: MEC/SEED, 2005. p. 22-31.

VALENTE, J. A; ALMEIDA, F. J. de. Visão analítica da informática na educação no Brasil: a questão da formação do professor. Revista Brasileira de Informática na Educação, Porto Alegre, n. 1, p. 45-60, 1997.

VELANGA, C. T. Formação de professores a distância: a construção do curso de pedagogia na Universidade Federal de Rondônia: limites e utopias. Humaitá, AM, v. 5, n. 2, p. 134-157, 2010.

Carla Busato Zandavalli, doutora em educação pela Universidade Federal de Mato Grosso do Sul (UFMS), é professora adjunta da UFMS. Participa do grupo de pesquisa Universitas/Ries, do Grupo de Estudos e Pesquisa em Políticas de Educação Superior (Geppes) e do Grupo de Estudos e Pesquisa em Educação Aberta e a Distância (Gepead), Campo Grande, Mato Grosso do Sul, Brasil.

Carlabzandavalli@gmail.com

Dirceu Martins Pedrosa, acadêmico do curso de Pedagogia, da modalidade a distância, polo de Bataguassu, Mato Grosso do Sul, Brasil. dirkmp49@gmail.com

Recebido em 7 de agosto de 2013.

Aprovado em 11 de março de 2014. 